\title{
Experimental and theoretical studies of 2-cyano-N-(4- morpholinobenzyldine) acetohydrazide as corrosion inhibitor for galvanized steel and 304 stainless steel in $\mathrm{1M} \mathrm{H}_{2} \mathrm{SO}_{4}$ solution
}

\author{
Ghalia A. Gaber ${ }^{1}$, Shimaa Hosny ${ }^{2}$, Lamiaa Z. Mohamed ${ }^{3, *}$ \\ ${ }^{1}$ Department of Chemistry, Faculty of Science (Girls), Al-Azhar University, P.O. Box: 11754, Yousef \\ Abbas Str., Nasr City, Cairo, Egypt \\ ${ }^{2}$ Chemistry Department, Faculty of Science, New Valley University, El-Kharga, 72511, Egypt \\ ${ }^{3}$ Mining, Petroleum and Metallurgical Engineering Department, Faculty of Engineering, Cairo \\ University, Egypt \\ *E-mail: lamylomy@yahoo.com
}

Received: 20 August 2021 / Accepted: 22 September 2021 / Published: 10 November 2021

\begin{abstract}
A 2-cyano-N-(4-morpholinobenzyldine) acetohydrazide is used as a corrosion inhibitor for both galvanized steel (GS) and 304 stainless steel (304 SS) in $1 \mathrm{M} \mathrm{H}_{2} \mathrm{SO}_{4}$. The corrosion inhibition efficiency of GS and $304 \mathrm{SS}$ in $1 \mathrm{M} \mathrm{H} \mathrm{H}_{2} \mathrm{SO}_{4}$ were studied using both chemical (weight-loss (WL)) and electrochemical techniques. The obtained results were used for calculating the inhibition effectiveness, corrosion rate (CR), and adsorption characteristics. The inhibitors adhere to the Langmuir adsorption isotherm on the investigated different surfaces. The SEM micrographs were investigated of GS and 304 SS with and without inhibitors at optimum conditions. The inhibitor led to a smooth and dense protective layer formation. Quantum chemical investigation of 2-cyano-N-(4-morpholinobenzyldine) acetohydrazide was studied.
\end{abstract}

Keywords: Corrosion inhibitor; Galvanized steel; 304 stainless steel; Acidic solution; 2-cyano-N-(4morpholinobenzyldine) acetohydrazide

\section{FULL TEXT}

(C) 2021 The Authors. Published by ESG (www.electrochemsci.org). This article is an open access article distributed under the terms and conditions of the Creative Commons Attribution license (http://creativecommons.org/licenses/by/4.0/). 